\title{
Distribution of maxillofacial fracture treatment using a titanium plate
}

\author{
Nicky Arviana*, Endang Sjamsudin*, Abel Tasman Yuza* \\ *Department of Oral and Maxillofacial Surgery Faculty Of Dentistry Universitas Padjadjaran
}

\begin{abstract}
Introduction: Maxillofacial fracture is a condition of the facial bones discontinuity in the mandible, maxilla, nasal, zygoma, palate, frontal and orbital. Treatment method of maxillofacial fractures is a close reduction or open reduction by internal fixation using titanium plates. This study was aimed to describe the fixation of maxillofacial fractures using titanium plates and also, to determine the further use of titanium plates as a fixation device at the Department of Oral and Maxillofacial Surgery, Faculty of Dentistry Universitas Padjadjaran and Hasan Sadikin Hospital. Methods: The research was a descriptive retrospective study with accidental sampling technique on the maxillofacial fracture fixation cases using titanium plates at the Department of Oral and Maxillofacial Surgery Hasan Sadikin Hospital. The samples were 135 medical records diagnosed with maxillofacial fractures. Results: The result shows that the use of titanium plates were $\mathbf{8 2 . 2 4 \%}$ of the total maxillofacial fracture cases. Conclusion: There are 135 patients with a diagnosis of maxillofacial fractures treated at the Oral and Maxillofacial Surgery, Faculty of Dentistry Universitas Padjadjaran and Hasan Sadikin Hospital in 2006-2010. Most cases were treated with open reduction (108 cases) and fixed by using a titanium plate ( 88 cases) as well as the combination of a titanium plate with a wire (12 cases).
\end{abstract}

Keywords: Maxillofacial fractures, titanium plate, open reduction, fixation devices, internal fixation.

\section{INTRODUCTION}

Maxillofacial fractures are often found in connection with the increased rate of traffic accidents, violence, and disasters in Indonesia. Fractures are the discontinuity of the bones forming the face such as the mandible, maxilla, nasal bone ( nasal), cheekbone ( zygoma), palate, frontal bone and orbital bone. ${ }^{1}$ Maxillofacial fracture includes midface fracture and mandibular fractures. The part of the face that usually fractures is the nasal bone, maxilla, mandible, and cheekbone ( zygoma). As many as $75 \%$ of cases of maxillofacial fractures occur in the mandible, zygoma, and nose. ${ }^{2}$

Mandibular fractures are more common than other fractures in the facial bones. ${ }^{3}$ Most fractures of the mandible occur because of sports (31.5\%) and motor vehicle accidents (27.2\%). ${ }^{2}$ The leading cause of maxillofacial fracture is accidents, violence, and fall. ${ }^{4}$

The principle of treatment in maxillofacial fractures include reduction measures that restore bone fracture position to its normal position, fixation is to maintain the position of bone fragments that have been reduced not to move 
back, and immobilization is resting of bone fragments from moving until healing is complete. ${ }^{1}$

Fixation devices that are commonly used in the treatment of maxillofacial fractures are IMF (intermaxillary fixation), intraosseus wiring, and titanium plate. The use of titanium plates is currently used for the fixation of maxillofacial fractures because it is rated more stable and faster process. ${ }^{5}$ Titanium is a material that is considered to be biocompatible with the body tissue and is the gold standard for maxillofacial fracture fixation devices. Titanium plates are used as fracture fixation devices in the form of maxillofacial miniplate or microplate. ${ }^{6}$ Both types of this plate have advantages over other internal tools fixation, that is structurally strong, thin and impalpable. ${ }^{7}$ Miniplate and microplate can be manipulated easily by the operator using pliers to follow the contours of bone so that it can provide an optimal adaptation. ${ }^{8}$

The usage of titanium makes it possible for a patient to open his mouth immediately after installation due to not using intermaxillary plate fixation (IMF), or the use of relatively short so as not to restrict the movement of the patient's mouth. ${ }^{1}$ Titanium plate as a means of fixation, the price is still relatively high as compared with the use of wires. ${ }^{9}$

Dr. Hasan Sadikin RSUP was established on October 8, 1967, and is a government hospital which was used as a place of education for Faculty of Medicine and Dentistry, University of Padjadjaran, Bandung. Oral and Maxillofacial Surgery Faculty of Dentistry, University of Padjadjaran - RSUP Dr Hasan Sadikin handle cases related with infection, dentoalveolar surgery, neoplasms and cysts, trauma, orthognathic surgical and osteodistraction, congenital anomalies, anaesthesia and special dental care, TMJ disorders, and disorders of the glands and nerves.

Dr Hasan Sadikin hospital is also a reference to the handling and treatment of maxillofacial fractures in the area of West Java, especially in Bandung. Based on the research conducted by Mohd Salman Bin Masri in 2009 concerning the Distribution of Cases Emergencies in the Department of Oral Surgery, RSUP dr. Hasan Sadikin for the period 2006-2007, trauma has the largest percentage of cases, i.e. $83 \%$, while $17 \%$ of them are cases of infection. From $83 \%$ of the cases of injury, fracture of the mandible is the most common fracture as much as 184 patients, followed by the fracture of the maxilla of 60 patients and the last is a combination of the maxillary and mandibular fractures as many as 13 patients. Patients treated in the Oral and Maxillofacial Surgery Department from different society who pay on their own or through insurance, including people are not able to bring information JAMKESMAS, Jamkesda, and SKTM (Certificate Disadvantaged).

Maxillofacial trauma and fracture cases have a reasonably high percentage of cases in RSUP dr. Hasan Sadikin. This study was aimed to describe the fixation of maxillofacial fractures using titanium plates and also, to determine the further use of titanium plates as a fixation device at the Department of Oral and Maxillofacial Surgery, Faculty of Dentistry Universitas Padjadjaran and Hasan Sadikin Hospital.

\section{METHODS}

The method used in this research was descriptive retrospective techniques using accidental sampling as the sampling technique. The procedure of the research was by collecting medical records card of patients who came to the Department of Oral and Maxillofacial Surgery, Faculty of Dentistry Universitas Padjadjaran, Hasan Sadikin Hospital from January 1, 2006, until December 31, 2010, was examined and the number of patients with fractures maxillofacial, age and sex of the patients with maxillofacial fractures, the number of patients who were treated with open reduction, and the number of patients that were fixed with plate, wire, and the combination of plate and wire was recorded. These data were then processed by frequency. Presentation of data prepared simply and presented in the form of a frequency distribution table, graph, and the calculation of percentages. The research was conducted from February 20, 2012, until March 14, 2012

\section{RESULTS}

There were 179 patients diagnosed with maxillofacial fractures in the period of 2006-2010. From these data, 29 patients had incomplete medical record data, refusing to take any 
treatment from the specialists at the Department of Oral and Maxillofacial Surgery, and patients who go home forcibly. Noted also 15 people with the diagnosis of dentoalveolar fractures, action

Table 1. Number of cases of maxillofacial fractures in 20062010

\begin{tabular}{lll}
\hline Year & Number & Percentage \\
\hline 2006 & 11 & $8.15 \%$ \\
2007 & 26 & $19.26 \%$ \\
2008 & 25 & $18.51 \%$ \\
2009 & 50 & $37.04 \%$ \\
2010 & 23 & $17.04 \%$ \\
\hline Total & 135 & $100 \%$ \\
\hline
\end{tabular}

alveolectomy, and action condylectomy without using a plate. From the overall data, the remaining 135 people who have complete data in the form of

Table 2. Sex distribution of maxillofacial fracture patients in 2006-2010

\begin{tabular}{cccc}
\hline Year & Female & Male & Number \\
\hline 2006 & 3 & 8 & 11 \\
2007 & 2 & 24 & 26 \\
2008 & 4 & 21 & 25 \\
2009 & 7 & 43 & 50 \\
2010 & 5 & 18 & 23 \\
\hline Total & 21 & 114 & 135 \\
\hline Persentase & $15.56 \%$ & $84.44 \%$ & $100 \%$ \\
\hline
\end{tabular}

Table 3. Age distribution of maxillofacial fracture patients in 2006-2010

\begin{tabular}{|c|c|c|c|c|c|c|c|c|}
\hline Year & $0-10$ yo & $11-20$ yo & $21-30$ yo & $31-40$ yo & $41-50$ yo & $51-60$ yo & $>60$ yo & Number \\
\hline 2006 & 0 & 6 & 3 & 2 & 0 & 0 & 0 & 11 \\
\hline 2007 & 1 & 5 & 13 & 3 & 3 & 1 & 0 & 26 \\
\hline 2008 & 1 & 9 & 9 & 5 & 1 & 0 & 0 & 25 \\
\hline 2009 & 1 & 18 & 21 & 5 & 4 & 0 & 1 & 50 \\
\hline 2010 & 1 & 9 & 8 & 2 & 3 & 0 & 0 & 23 \\
\hline Jumlah & 4 & 47 & 54 & 17 & 11 & 1 & 1 & 135 \\
\hline Persentase & $2.96 \%$ & $34.82 \%$ & $40 \%$ & $12.59 \%$ & $8.15 \%$ & $0.74 \%$ & $0.74 \%$ & $100 \%$ \\
\hline
\end{tabular}

Table 4. Distribution of type and location in maxillofacial fracture patients of 2006-2010

\begin{tabular}{|c|c|c|c|c|c|c|c|}
\hline \multirow{2}{*}{ Type of fracture } & \multicolumn{5}{|c|}{ Year } & \multirow{2}{*}{$\frac{\text { Number }}{\text { Number }}$} & \multirow{2}{*}{$\%$} \\
\hline & 2006 & 2007 & 2008 & 2009 & 2010 & & \\
\hline \multicolumn{8}{|c|}{ Type of maxillofacial fracture } \\
\hline Mandibular & 4 & 14 & 19 & 25 & 14 & 76 & 56.3 \\
\hline Maxillary & 1 & 4 & 1 & 5 & 3 & 14 & 10.37 \\
\hline Combination & 4 & 7 & 5 & 19 & 5 & 40 & 29.63 \\
\hline ZMC Complex & 0 & 0 & 0 & 1 & 1 & 2 & 1.48 \\
\hline NOE Complex & 0 & 0 & 0 & 0 & 0 & 0 & 0 \\
\hline Panfacial & 2 & 1 & 0 & 0 & 0 & 3 & 2.22 \\
\hline Total & 11 & 26 & 25 & 50 & 23 & 135 & 100 \\
\hline \multicolumn{8}{|c|}{ Location of maxillofacial fracture } \\
\hline Condyle & 0 & 0 & 0 & 0 & 1 & 1 & 1.32 \\
\hline Angulus & 0 & 1 & 0 & 2 & 1 & 4 & 5.26 \\
\hline Ramus & 0 & 0 & 0 & 0 & 0 & 0 & 0 \\
\hline Symphysis & 1 & 2 & 1 & 1 & 2 & 7 & 9.21 \\
\hline Coronoid process & 0 & 0 & 0 & 1 & 0 & 1 & 1.32 \\
\hline Corpus & 0 & 3 & 4 & 0 & 0 & 7 & 9.21 \\
\hline Parasymphisis & 1 & 2 & 7 & 6 & 3 & 19 & 25 \\
\hline Multiple & 1 & 5 & 6 & 13 & 6 & 31 & 40.79 \\
\hline Unidentified & 1 & 1 & 1 & 2 & 1 & 6 & 7.89 \\
\hline Total & 4 & 14 & 19 & 25 & 14 & 76 & 100 \\
\hline
\end{tabular}


Table 6. Type of maxillofacial fracture distribution of patients in 2006-2010

\begin{tabular}{|c|c|c|c|c|c|c|c|}
\hline Type & & & Year & & & Number & $\%$ \\
\hline & 2006 & 2007 & 2008 & 2009 & 2010 & & \\
\hline Segmental maxillary & 0 & 2 & 0 & 0 & 1 & 3 & 21.43 \\
\hline Le Fort I & 0 & 0 & 0 & 2 & 1 & 3 & 21.43 \\
\hline Le Fort II & 0 & 2 & 0 & 2 & 0 & 4 & 28.57 \\
\hline Le Fort III & 0 & 0 & 0 & 0 & 0 & 0 & 0 \\
\hline Palate & 0 & 0 & 0 & 0 & 0 & 0 & 0 \\
\hline Multiple & 1 & 0 & 1 & 1 & 1 & 4 & 28.57 \\
\hline Number & 1 & 4 & 1 & 5 & 3 & 14 & 100 \\
\hline
\end{tabular}

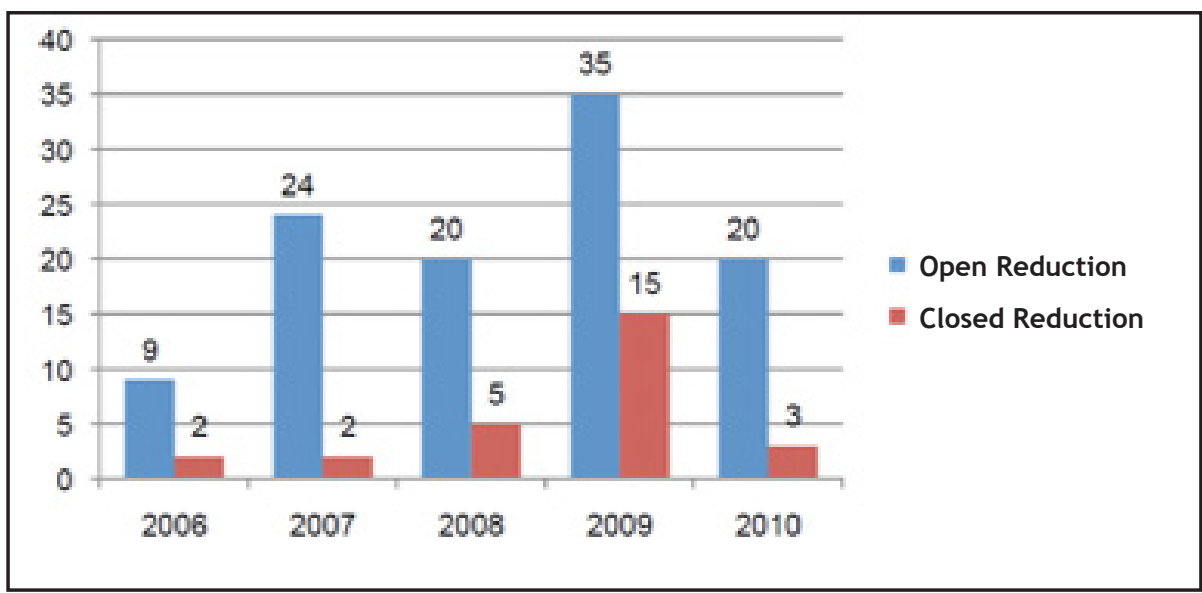

Figure 1. Type of maxillofacial fracture reduction in 2006-2010

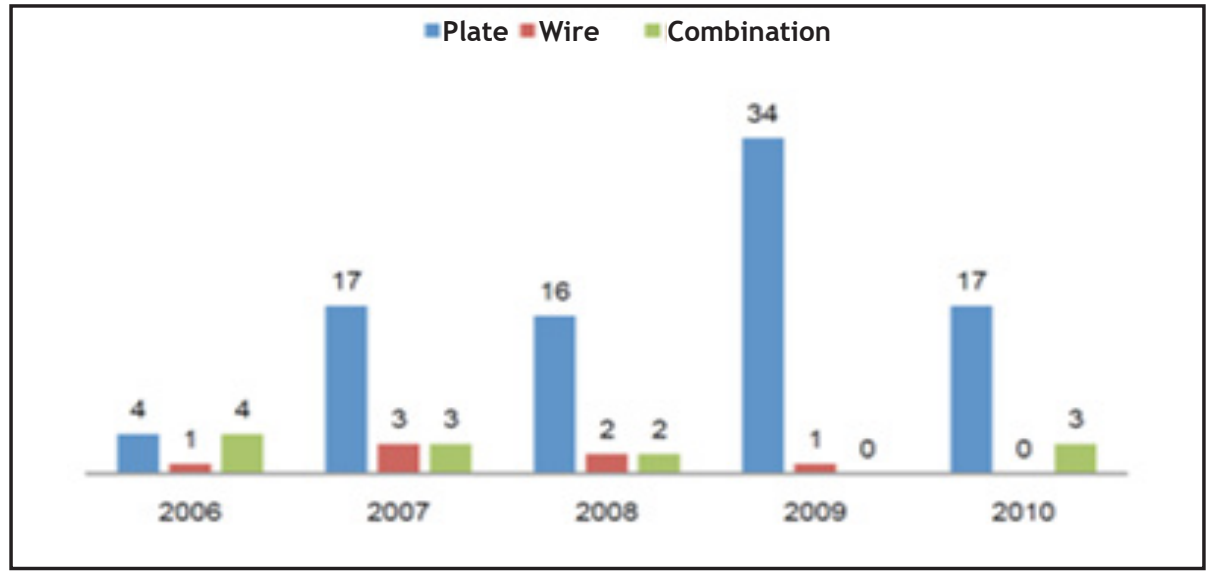

Figure 2. Type of internal fixation appliance for maxillofacial fracture patients in 2006-2010

working diagnosis, reduction measures, the type of fixation devices used and necessities of the name, age, sex, and year of inspection.

\section{DISCUSSION}

The number of patients who come in with maxillofacial fractures and got treatment in the
Department of Oral Surgery and Maxillofacial Faculty Dentistry, University of Padjadjaran Hospital dr. Hasan Sadikin during the period from 1 January 2006 to 31 December 2010 was 135 patients (Table 1). Percentage of patients with maxillofacial fractures in the year 2006 showed minimal amounts. This is due to the five years cycle storage medical records of patients in $\mathrm{dr}$. 
Hasan Sadikin hospital making the medical records in 2006 hard to find, many scattered or lost, and some have been destroyed.

Patients with maxillofacial fractures was found most in the age interval 21-30 years, i.e. $54(40 \%)$ cases, followed by the age range of $11-20$ years $(34.82 \%)$ and the age range of $31-40$ years (12.59\%) (Table 2). This situation is similar to the research conducted at the Hospital Dr Cipto Mangunkusumo Jakarta. ${ }^{10}$ This is because in the age range of 21-40 years are productive age, the risk of accidents is where outdoor activities are often carried out as work, exercise, and driving. According to research conducted by Miloro et al. ${ }^{3}$, the age range of 21-30 years has recorded the highest number of cases of maxillofacial fractures. On a study conducted by Shahim et al. ${ }^{11}$ the age range of 15-24 years has recorded the highest number of cases of maxillofacial trauma (26.7\%), followed by the age range of 25-34 years (21.5\%), and the age range of $35-44$ years (14.3\%).

Male patients suffer maxillofacial fractures of the patients were female, amounting to 114 (84.44\%) patients of all patients maxillofacial fractures (Table 3 ), it is because of men more active outside the home, more exercise, more use of motor vehicles, and increased risk of accidents that cause trauma to the face. According to the study Shahim et al. ${ }^{11}$ in Melbourne, a motor vehicle accident. The main factors causing trauma Maxillofacial (69\%), was followed by a fall $(15 \%)$ and violence (of $10 \%) .{ }^{11}$

Mandibular fracture is the type of fracture that is most common from 2006 to 2010, which is $76(56.3 \%)$ cases out of 135 cases of maxillofacial fractures (Table 4). The high prevalence of this case is due to the position of the mandibular bone, which is more outward and more prominent than other facial bone-forming bones. ${ }^{3}$ According to research conducted by Singh et al. ${ }^{12}$, motor vehicle accidents are the most common cause of mandibular fracture is equal to $70 \%$. In this study found no fracture NOE Complex. ${ }^{12}$

Multiple mandibular fractures, the fractures of the mandible in two or more locations are cases in the whole of 2006-2010 with the number 31 $(40.79 \%)$ cases (Table 5 ). Parasimfisis fracture is a fracture with the second largest number of 19 $(25 \%)$ cases, while the rami fracture was not found at all. According to Miloro et al. ${ }^{3}, 50 \%$ of cases in the mandible fractures are multiple fractures.

In this research, there are many numerous mandibular fractures. This is because there is indirect fracture which is a fracture on the area far from the location of the main fracture, for example, the force occurs on the left side of the angulus mandible which causes direct fracture in that area, and a fracture occurs indirect or indirect on the right side mandibular corpus is related to the mechanical properties of the mandibular bone caused by impaction force when the trauma occurred. ${ }^{3}$ The mandible will be crooked into and produces compression forces on the impacted area and tensile strength ( tensile) the media area opposite to the affected area. When a tensile force ( tensile) is greater than the force of resistance of the mandible, the fracture will occur, originated from the media, then walked toward the affected area impaction. ${ }^{3}$

There are 8 compound, or comminuted fracture because the force of which is higher than the trauma caused by physical violence. Fractures caused by the wide and blunt objects tend to create multiple fractures, for example, symphysis and condyle fracture. ${ }^{8}$ According to research conducted, motor vehicle accidents usually cause this type of multiple fractures, number of cases are caused by the position of the mandible bone that is more outgoing and more prominent than the other bones.

Maxillary fractures that occurred in the years 2006-2010 amounted to 14 cases (Table 6). Multiple fractures and Le Fort II fractures have respectively 4 (28.57\%) cases and segmental maxillary fractures and fractures of Le Fort respectively 3 (21.43\%) cases. Le Fort III fracture and fractured palate was not found in the study. Usually, the palate fractures most often occur in combination with other facial fractures central part of such a fracture Le Fort. ${ }^{8}$

Open reductions dominate repositioning technique of the fracture fragments with the number of $108(80 \%)$ cases (Figure 1). Research conducted by Shahim et al. ${ }^{11}$ shows that the technique of open reduction with internal fixation is mostly done in cases of mandibular fractures (26.9\%) which were associated with a number of mandibular fractures and are most often found in 
the study. Open reduction technique is now more widely used because it can improve the function and aesthetic better than closed reduction techniques. ${ }^{7}$ Open reduction also reduces the risk of malocclusions often occurs in cases of mandibular condyle fracture. ${ }^{3}$

From 107 cases of open reduction (one example is a case of using reduction techniques open however fixed with use interdental wire, till one out of 108 cases is not fixed internally), the use of plate fixation is most used as many as 88 $(82.24 \%)$ cases (Figure 2). Use of the plate today is more recommended because it is more stable, fast workmanship, faster functional recovery, and relieves pain. ${ }^{5,13}$ The plates are relatively more expensive than the use of wires, but the results of this study, $82.24 \%$ of cases of maxillofacial fractures were fixed by using a plate. The high number of cases of maxillofacial fractures were fixed using this plate might be due to JAMKESMAS facility, Askes, or Gakin card is available in dr. Hasan Sadikin, so that the poor too can get the fixed maxillofacial fracture treatment using a plate.

\section{CONCLUSION}

There are 135 patients with a diagnosis of maxillofacial fractures treated at the Oral and Maxillofacial Surgery Department of the Faculty of Dentistry Universitas Padjadjaran and Hasan Sadikin Hospital during 2006-2010. Most treatments performed are open reduction (108 cases), fixed by using a titanium plate ( 88 cases), and also the combination of titanium plate with a wire (12 cases).

\section{REFERENCES}

1. Hupp J, Ellis E, Tucker M. Contemporary oral and maxillofacial surgery $7^{\text {th }}$ ed. Missouri: Mosby Elsevier. 2008.

2. Sharabi SE, Koshy JC, Thornton JF, Hollier LH
Jr. Facial Fractures. Plast Reconstr Surg. 2011 Feb;127(2):25e-34e.

3. Miloro M, Ghala G, Larsen P, Waite P. Peterson's Principles of Oral and Maxillofacial Surgery $2^{\text {nd }}$ ed. Ontario: BC Decker Inc. 2004.

4. Hogg NJ1, Stewart TC, Armstrong JE, Girotti MJ. Epidemiology of maxillofacial injuries at trauma hospital in Ontario, Canada, between 1992 and 1997. J Trauma. 2000 Sep;49(3):42532.

5. Haers PE, Oechslin C, Sailer HF. Is wire osteosynthesis obsolete for fixation of Le Fort 1 osteotomies? Oral Surg Oral Med Oral Pathol Oral Radiol Endod. 1999 Oct;88(4):391-4.

6. Dorri M, Nasser M, Oliver R. Resorbable versus titanium plates for facial fractures. Cochrane Database of Systematic Reviews. Cochrane Database Syst Rev. 2009 Jan 21;(1):CD007158.

7. Balaji SM. Textbook of oral and maxillofacial surgery. India: Elsevier. 2007.

8. Fonseca RJ. Oral and maxillofacial trauma $3^{\text {rd }}$ ed. Vol 2. Missouri: Elsevier Saunders. 2005.

9. Murtedjo U. Penggunaan miniplate pada pelatanaksaan fraktur maksilofasial. Simposia 2007;7(1). Available at http://www.majalahfarmacia.com (Diakses 17 November 2011).

10. Mulyaningsih D. Gambaran kasus bedah mulut di divisi bedah mulut perjan Rumah Sakit Dr. Cipto Mangunkusumo Jakarta Periode Januari 2000-Desember 2004. Skripsi. Bandung: Fakultas Kedokteran Gigi Universitas Padjadjaran. 2005.

11. Shahim FN, Cameron P, McNeil JJ. Maxillofacial trauma in major trauma patients. Aust Dent J. 2006 Sep;51(3):225-30.

12. Singh RK, Pal US, Agrawal A, Singh G. Single miniplate osteosynthesis in angle fracture. Natl J Maxillofac Surg. 2011 Jan-Jun; 2(1): 47-50.

13. Chaushu G, Manor Y, Shoshani Y, Taicher S. Risk factor contributing to symptomatic plate removal in maxillofacial trauma patients. Plast Reconstr Surg. 2000 Feb;105(2):521-5. 